\title{
ALLOZYME VARIATION IN TWO NATURAL POPULATIONS OF DAPHNIA PULEX*
}

\author{
EDWARD BERGER+ \\ Biology Department, Dartmouth College, Hanover, New Hampshire \\ and \\ JAMES SUTHERLAND
}

Biology Department, State University of New York ot Albany, Albany, New York

Received 24.x.77

\section{SUMmary}

\begin{abstract}
Gene-enzyme variation was examined at a number of allozyme loci, in two natural populations of Daphnia pulex. Both quantitative and qualitative differences were uncovered between the two populations. Temporal studies of variation, at three polymorphic loci, in a permanent population from Saratoga Lake revealed considerable fluctuations in allele and genotype frequency. The possible forces at work to produce these fluctuations are discussed. Genetic evidence is presented supporting the contention that parthenogenesis in this species is ameiotic. No consistent pattern of excess heterozygosity was observed in $D$. pulex.
\end{abstract}

\section{Introduction}

The cladoceran, Daphnia pulex, represents a major component of the zooplankton community in many temperate lakes and ponds (Brooks, 1957). Through most of the year reproduction in this species is parthenogenetic, however, in many populations one or two generations occur in which diapausing eggs are produced. These eggs, enclosed in the ephippium, a modification of the maternal carapace, are thought to represent a sexual phase, since their appearance in the population is generally associated with the production of fertile males (Banta and Brown, 1929). In some populations the ephippial phase occurs only in the fall, and these populations are designated "fall monocycles". In other populations ephippial carrying females are seen only in the spring ("spring monocycles "), and in others they appear in both fall and spring ("dicycle" type). Finally, some populations seem to lack an ephippial generation entirely. In large permanent bodies of water where $D$. pulex adults persist all year round, ephippia simply contribute to the standing population. In small ponds, which freeze over or dry up periodically, the population is regenerated entirely from diapausing ephippial eggs.

To a population geneticist $D$. pulex has several features which make it peculiar and interesting. For example, it is not clear, for this species, whether parthenogenesis is mictic, involving some sort of meiotic cycle, or apomictic, that is, truly mitotic. Indirect evidence supporting both interpretations is available for D. pulex (Mortimer, 1936; Ojima, 1958; Bacci

* Supported in part by an NSF grant (22866) to E. B.

$\dagger$ To whom all correspondence should be sent. 
et al., 1961). In D. magna Hebert and Ward (1972) have shown parthenogenesis to be apomictic. Similarly, it has not yet been shown conclusively in $D$. pulex that the diapausing ephippial generation results from the fusion of haploid gametes. Indeed, ephippia do appear to be produced in laboratory populations in the total absence of males.

One important evolutionary question for which Daphnia are useful involves assessing the effect of parthenogenetic reproduction on the genetic structure of populations. Specifically, this system makes it possible to estimate, under particularly suitable conditions, the extent to which single locus heterosis occurs in nature (Berger, 1976).

The work described below is a survey of genetic variation, over space and time, at several allozyme loci in two natural populations of $D$. pulex. The major conclusion to be drawn is that in $D$. pulex parthenogenesis is apomictic, and that the genetic structure of one large and permanent $D$. pulex population studied for almost 2 years showed significant temporal instability, but no major and consistent tendency to heterotic selection.

\section{Materials and methods}

(i) Collections

Daphnia pulex were collected with a No. 10 plankton net, with a $10^{\prime \prime}-$ mouth diameter, taken by net haul from a rowing boat. Samples were stored in filtered pond water at $4^{\circ} \mathrm{C}$ until use, or frozen and stored at $-18^{\circ} \mathrm{C}$. For some studies Glarke-Bumpus collectors were employed. The two populations sampled were: (1) Saratoga Lake-a large permanent lake in New York State containing a spring monocycle population, and (2) Campus Pond-a small ( 2 acre) lake containing a dicyclic population. Because of its shallowness Campus Pond freezes over during winter. In Saratoga sampling, care was taken to sample from approximately the same location each time, but we had no formal station established.

\section{(ii) Electrophoresis}

Electrophoresis, in 7 per cent acrylamide slab gels, was carried out according to the procedure of Hubby and Lewontin (1966). Staining procedures for the various enzymes are from Shaw and Prasad (1970) with minor modification. Individual Daphnia were homogenised in buffered sucrose, on ice, in an Adamkewicz Microhomogeniser and layered directly on to the gel.

\section{(iii) Genotype frequencies}

In order to determine whether the populations were in equilibrium, expected genotype frequencies were calculated from gene frequency data assuming Hardy-Weinberg conditions. Goodness of fit was evaluated by the chi-square test.

\section{Results}

(i) Gene enzyme variation in nature

An initial screening of 26 different enzyme staining systems was done for Daphnia pulex from two natural populations. For 14 enzyme staining procedures no activity could be detected in gels containing single Daphnia. 
These include isocitrate dehydrogenase (IDH), malic enzyme (ME), phosphoglucomutase (PGM), hexokinase (Hex), peptidase (Pep), sorbitol dehydrogenase (SDH), aldolase (Ald), adenylate kinase (Adk), 6-phosphogluconate dehydrogenase (6-PGD), fructose-1, 6-diphosphatase (FDP), and glucose-6-phosphate dehydrogenase $(\mathrm{Zw})$. Activity was observed for Drosophila homogenates which were included as controls. When mass homogenates of Daphnia were employed activity could be detected in most cases.

Of the 12 enzyme staining systems in which activity could be detected in homogenates of single Daphnia, seven produced invariant patterns. In each case a sample of at least 28 individuals from each population was studied. A single band of activity was found for xanthine dehydrogenase (XDH), general protein-3 (GP-3), tetrazolium oxidase (TO), fumarase (FUM), and glutamic oxaloacetic transaminase (GOT). There were two different malate dehydrogenase $(\mathrm{MDH})$ bands, designated $\mathrm{MDH}-\mathrm{A}$ and $\mathrm{MDH}-\mathrm{B}$, and two acid phosphatase (Acph) bands, designated Acph-A and Acph-B. We surmise that these represent a total of nine monomorphic loci.

Allozyme variation was clearly present in eight gene-enzyme systems. These included a phosphoglucose isomerase $(P G I)$ for which two alleles were found; two esterases, designated $E s t-A$ and $E s t-B$ with three alleles each; two alkaline phosphatases designated $A l k-A$ and $A l k-B$ with five and four alleles, respectively; and three leucine aminopeptidases, designated $L A P-A, L A P-B$, and $L A P-C$, with three, three, and two alleles, respectively. $A l k-A$ activity did not appear in all Daphnia, and will be excluded from further discussion. In a ninth system, lactate dehydrogenase $(L D H)$, two different banding patterns were seen after electrophoresis. One contained three bands, the other six. While this probably reflects allozyme variation, it may be explained by a model involving isozymes produced by duplicate genes. Excluding $L D H$ we have detected genetic variation at eight of 17 loci ( 47 per cent) a value comparable to other invertebrates (Lewontin, 1974).

\section{(ii) Genetic studies of parthenogenesis}

The first study was to determine whether or not parthenogenesis in $D$. pulex was apomictic. The data for two esterase loci, and alkaline phosphatase-B in Daphnia pulex, are summarised in table 1. Here we isolated a large number of single females, allowed them to produce broods in individual vials and then determined the genotype of each female, and her offspring. In each case the genotypes of individual parthenogenetic progeny were identical to their original female parent.

\section{(iii) Genetic variation in two populations}

Lake Saratoga was found to contain a spring monocycle population of $D$. pulex while our other site, Campus Pond, maintained a dicyclic population. Data comparing allelic variation in these two populations is summarised in table 2. Est- $A$ was found to be segregating two alleles in Saratoga, while the Campus Pond population had no zone of activity whatsoever in this region of the gel. This absence could either be due to an effect of the pond environment on gene expression or could represent a genetic difference. The first possibility seems unlikely for when clones of pond and lake 
TABLE 1

Analysis of parthenogenetic progeny from female Daphnia pulex of predetermined genotype. Individual females were isolated in shell vials, and allowed to produce a parthenogenetic brood. The female was removed and her genotype determined. The young brood was allowed to develop to full size and their genotypes determined

a.

Est- $A$
Genotype of $q$
$1 / 1$
$1 / 2$
$2 / 2$

b.

$E s t-B$
Genotype of $q$
$1 / 1$
$1 / 2$
$2 / 2$

c.

Number
of $\begin{gathered}\text { scored } \\ 11 \\ 15 \\ 14\end{gathered}$

Number of $q$ scored 6 13 1

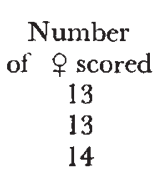

Genotype of progeny from clones

$\begin{array}{rrr}1 / 1 & 1 / 2 & 2 / 2 \\ 47 & 0 & 0 \\ 0 & 44 & 0 \\ 0 & 0 & 30\end{array}$

Genotype of progeny from clones

$\begin{array}{rrr}1 / 1 & 1 / 2 & 2 / 2 \\ 13 & 0 & 0 \\ 0 & 40 & 0 \\ 0 & 0 & 4\end{array}$

Genotype of progeny from clones

\begin{tabular}{crc} 
& \multicolumn{1}{c}{} & \\
$2 / 3$ & $2 / 4$ & $2 / 2$ \\
39 & 0 & 0 \\
0 & 41 & 0 \\
0 & 0 & 18
\end{tabular}

females were grown in the laboratory, in the same environment (temperature, light, water, food), the differences persisted.

At the Est-B locus the Saratoga population was found to be segregating two alleles, with heterozygotes displaying a two-banded pattern. The pond $D$. pulex were uniformly monomorphic for a slower moving allozyme, however, there were additional minor bands which were absent in the Saratoga population. These patterns were entirely heritable in clonal analysis as described above.

At the $P G I$ locus the Saratoga population was fixed for the $P G I^{2}$ allele. In the pond population 95 per cent of the individuals sampled were heterozygotes.

The $L D H$ pattern in Saratoga consisted of a three-banded phenotype. Since there was no variation it is impossible to determine whether this represents a homozygote or heterozygote phenotype. We simply refer to it as pattern 1. The pond population uniformly had a six-banded pattern, which included the three bands seen in Saratoga, plus three additional ones. We designate this pattern 2.

At the $L A P-C$ locus two alleles were segregating in Saratoga, while the Campus Pond was composed entirely of heterozygotes. Three alleles were segregating in Saratoga for $L A P-B$, while in the Campus Pond no activity could be detected among individuals in this region of the gel. As was the case for Est-A, clones derived from both populations, and maintained under identical conditions, continued to demonstrate these differences. Thus, the differences appear to be genetic and not environmental. LAP-A was found to be segregating three alleles in Saratoga while the Campus Pond was completely heterozygous for two of these alleles. 


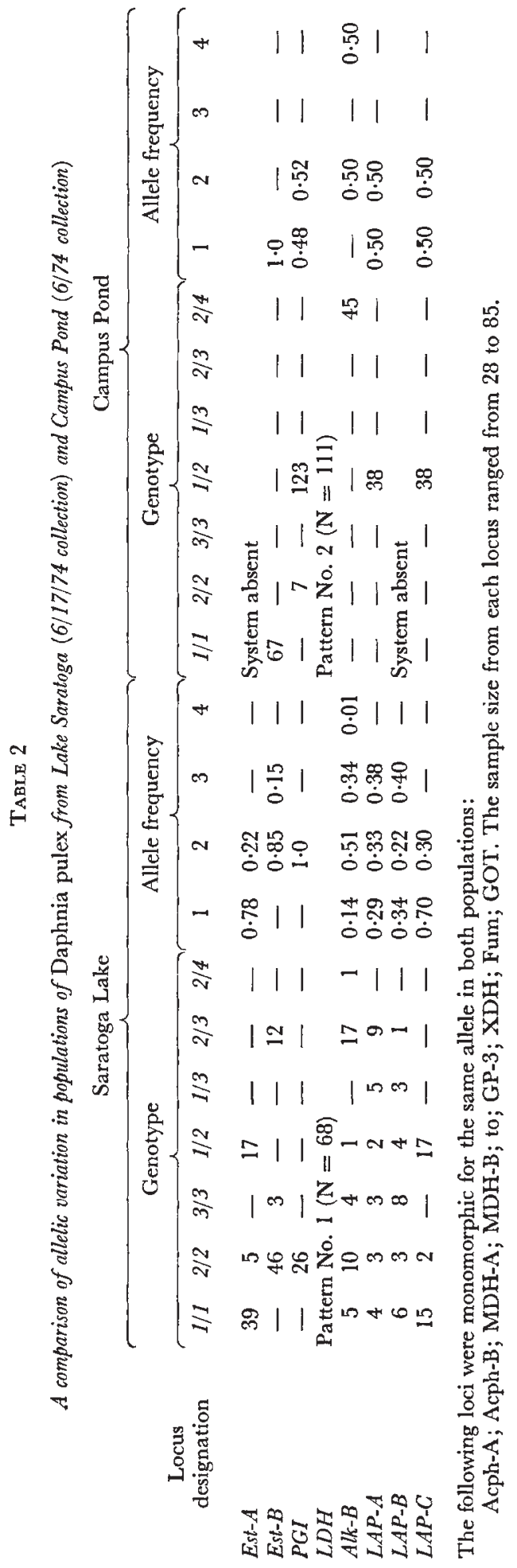

41/1-B 
Both populations were polymorphic for $A l k-B$, although, again, the Campus Pond was comprised entirely of hterozygotes (table 2). The major differences between the two $D$. pulex populations, in terms of their esterase and $L A P$ patterns, are puzzling, and may reflect the presence of two different races, or even species. Neither of the two populations contain $D$. pulicaria, the species most easily confused with $D$. pulex.

\section{(iv) Variation over time}

In order to evaluate the stability of the gene pool over time we undertook a study in which gene-enzyme variation was followed over an 18month period in Lake Saratoga. The gene frequency data for three loci are summarised in fig. 1. Allele frequencies at the Est-B locus varied
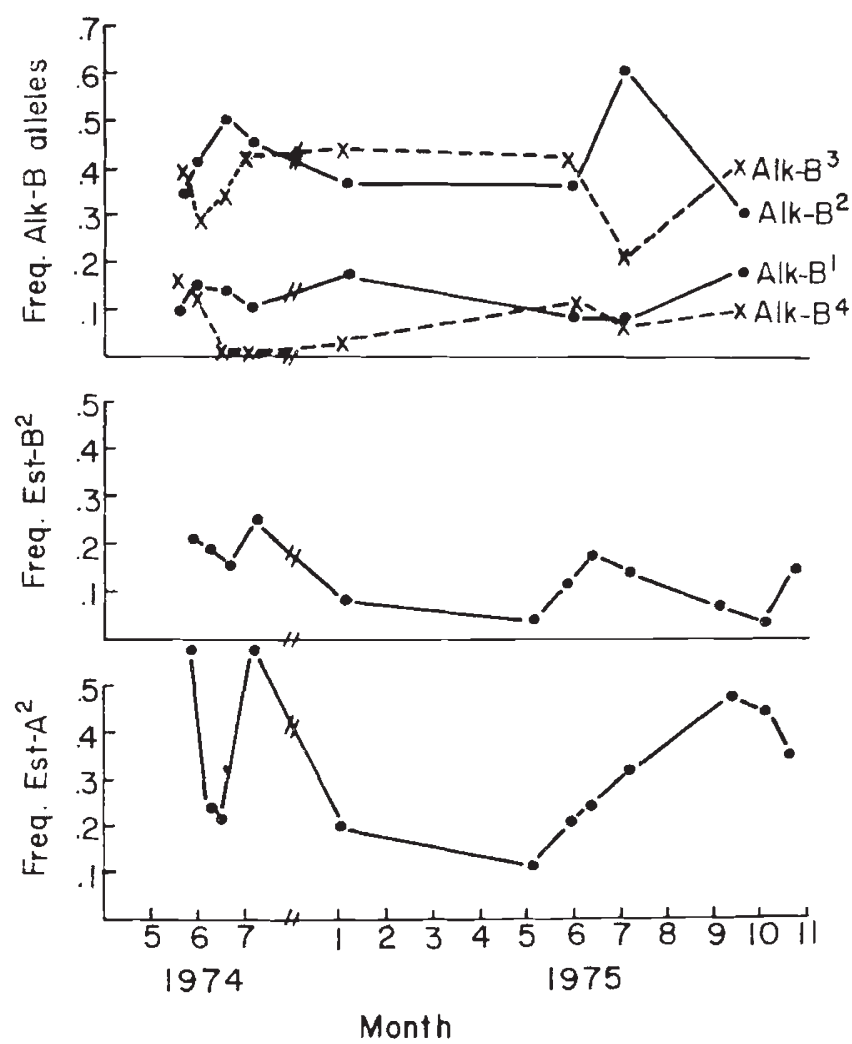

Fig. 1.-Allele frequencies at three polymorphic loci in collections of Daphnia pulex from Saratoga Lake during 1974 and 1975. Full details on sample size and genotype frequencies can be found in tables 3 to 5 .

slightly, however, large fluctuations were observed for Est-A, and $A l k-B$. We do not have enough time points to know whether any of these fluctuations occur cyclically, or whether variations at different loci are correlated.

Even more pronounced fluctuations were found when genotype frequencies were examined (tables 3-5). For example, the frequency of the $A l k-B^{2 / 3}$ 
TABLE 3

Temporal analysis of genotype and allele frequency at the Esterase A locus of Lake Saratoga Daphnia pulex. Alleles: numbered with increasing mobility on gels

\begin{tabular}{|c|c|c|c|c|c|c|c|c|}
\hline \multirow{2}{*}{$\begin{array}{c}\text { Collection } \\
\text { Date }\end{array}$} & \multicolumn{3}{|c|}{ Genotype frequency } & \multirow{2}{*}{$\begin{array}{c}\text { Sample } \\
\mathrm{N}\end{array}$} & \multicolumn{2}{|c|}{ Allele frequency } & \multirow{2}{*}{$\begin{array}{l}\text { Observed No. of } \\
\text { heterozygotes }\end{array}$} & \multirow{2}{*}{$\begin{array}{l}\text { Expected No. of } \\
\text { heterozygotes }\end{array}$} \\
\hline & $1 / 1$ & $1 / 2$ & $2 / 2$ & & 1 & 2 & & \\
\hline $5 / 28 / 74$ & $0 \cdot 30$ & $0 \cdot 20$ & 0.50 & 49 & 0.41 & 0.59 & 10 & $24 *$ \\
\hline $5 / 6 / 74$ & $0 \cdot 72$ & 0.08 & $0 \cdot 20$ & 40 & 0.76 & $0 \cdot 24$ & 3 & $15 *$ \\
\hline $6 / 17 / 74$ & 0.64 & $0 \cdot 28$ & $0 \cdot 08$ & 61 & 0.78 & $0 \cdot 22$ & 17 & 21 \\
\hline $7 / 1 / 74$ & $0 \cdot 16$ & $0 \cdot 50$ & $0 \cdot 34$ & 32 & 0.41 & 0.59 & 16 & 15 \\
\hline $1 / 3 / 75$ & 0.74 & $0 \cdot 12$ & $0 \cdot 14$ & 73 & 0.80 & $0 \cdot 20$ & 9 & $23^{*}$ \\
\hline $5 / 3 / 75$ & $0 \cdot 86$ & $0 \cdot 03$ & $0 \cdot 11$ & 35 & 0.87 & $0 \cdot 13$ & 1 & $8 *$ \\
\hline $5 / 29 / 75$ & $0 \cdot 75$ & $0 \cdot 05$ & $0 \cdot 20$ & 40 & $0 \cdot 78$ & $0 \cdot 21$ & 2 & $14 *$ \\
\hline $6 / 13 / 75$ & $0 \cdot 72$ & 0.06 & $0 \cdot 22$ & 18 & 0.75 & $0 \cdot 25$ & 1 & $7 *$ \\
\hline $7 / 1 / 75$ & 0.47 & $0 \cdot 41$ & $0 \cdot 12$ & 32 & $0 \cdot 67$ & $0 \cdot 33$ & 13 & 14 \\
\hline $9 / 16 / 75$ & 0.07 & 0.93 & 0 & 15 & $0 \cdot 53$ & 0.47 & 14 & 8* \\
\hline $10 / 1 / 75$ & $0 \cdot 10$ & $0 \cdot 90$ & 0 & 10 & $0 \cdot 55$ & $0 \cdot 45$ & 9 & $5 *$ \\
\hline $10 / 15 / 75$ & $0 \cdot 29$ & $0 \cdot 71$ & 0 & 17 & $0 \cdot 65$ & $0 \cdot 35$ & 12 & 8 \\
\hline
\end{tabular}

* Significant deviation at $0 \cdot 01$ level.

TABLE 4

Temporal analysis of genotype and allele frequency at the Esterase-B locus of Lake Saratoga Daphnia pulex. Alleles are numbered consecutively with increasing mobility on gels

\begin{tabular}{|c|c|c|c|c|c|c|c|c|}
\hline \multirow{2}{*}{$\begin{array}{l}\text { Collection } \\
\text { date }\end{array}$} & \multicolumn{3}{|c|}{ Genotype frequency } & \multirow{2}{*}{$\underset{\mathrm{N}}{\text { Sample }}$} & \multicolumn{2}{|c|}{ Allele frequency } & \multirow{2}{*}{$\begin{array}{l}\text { Observed No. of } \\
\text { heterozygotes }\end{array}$} & \multirow{2}{*}{$\begin{array}{l}\text { Expected No. of } \\
\text { heterozygotes }\end{array}$} \\
\hline & $1 / 1$ & $1 / 2$ & $2 / 2$ & & 1 & 2 & & \\
\hline $5 / 28 / 74$ & $0 \cdot 58$ & $0 \cdot 42$ & 0 & 50 & $0 \cdot 74$ & $0 \cdot 21$ & 21 & 16 \\
\hline $6 / 6 / 74$ & $0 \cdot 71$ & $0 \cdot 22$ & 0.07 & 41 & $0 \cdot 81$ & $0 \cdot 19$ & 9 & 13 \\
\hline $6 / 17 / 74$ & $0 \cdot 75$ & $0 \cdot 20$ & $0 \cdot 05$ & 61 & $0 \cdot 85$ & $0 \cdot 15$ & 12 & $16^{*}$ \\
\hline $7 / 1 / 74$ & $0 \cdot 66$ & $0 \cdot 23$ & $0 \cdot 11$ & 35 & $0 \cdot 75$ & $0 \cdot 25$ & 8 & 13 \\
\hline $1 / 3 / 75$ & $0 \cdot 84$ & $0 \cdot 16$ & 0 & 73 & 0.92 & $0 \cdot 08$ & 12 & 11 \\
\hline $5 / 3 / 75$ & 0.94 & 0.06 & 0 & 35 & 0.97 & 0.03 & 2 & 2 \\
\hline $5 / 29 / 75$ & $0 \cdot 77$ & $0 \cdot 20$ & 0.03 & 44 & 0.88 & $0 \cdot 12$ & 9 & 9 \\
\hline $6 / 13 / 75$ & $0 \cdot 68$ & $0 \cdot 26$ & 0.06 & 19 & $0 \cdot 82$ & $0 \cdot 18$ & 5 & 6 \\
\hline $7 / 1 / 75$ & $0 \cdot 72$ & $0 \cdot 28$ & 0 & 32 & 0.86 & $0 \cdot 14$ & 9 & 8 \\
\hline $9 / 16 / 75$ & $0 \cdot 87$ & $0 \cdot 13$ & 0 & 15 & 0.93 & $0 \cdot 07$ & 2 & 2 \\
\hline $10 / 1 / 75$ & 0.89 & $0 \cdot 11$ & 0 & 9 & 0.94 & $0 \cdot 06$ & 1 & l \\
\hline $10 / 15 / 75$ & 0.76 & $0 \cdot 18$ & $0 \cdot 06$ & 17 & $0 \cdot 85$ & $0 \cdot 15$ & 3 & 4 \\
\hline
\end{tabular}

* Significant deviation at $0 \cdot 05$ level.

heterozygote tripled in a 2-month period in the spring of 1974 . It is of interest to note that while the frequency of the $A l k-B^{2}$ allele rose to a peak in both June 1974, and July 1975, in 1974 it was the result of increases in the abundance of $2 / 2$ and $2 / 3$ genotypes, while in 1975 the increase in allele frequency was due almost entirely to the increase of $2 / 2$ homozygotes. Indeed, during this period the frequency of the $2 / 3$ heterozygote was actually declining. Once again, the data are insufficient to assess the presence of any regularities in the temporal pattern of variation, or correlated changes occurring at two or more loci.

Finally, we tested to see whether the population was in Hardy-Weinberg equilibrium during the period sampled, using chi-square analysis of observed and expected genotype frequencies. At the $A l k-B$ and $E s t-B$ loci the population was in Hardy-Weinberg equilibrium throughout most of the sample 


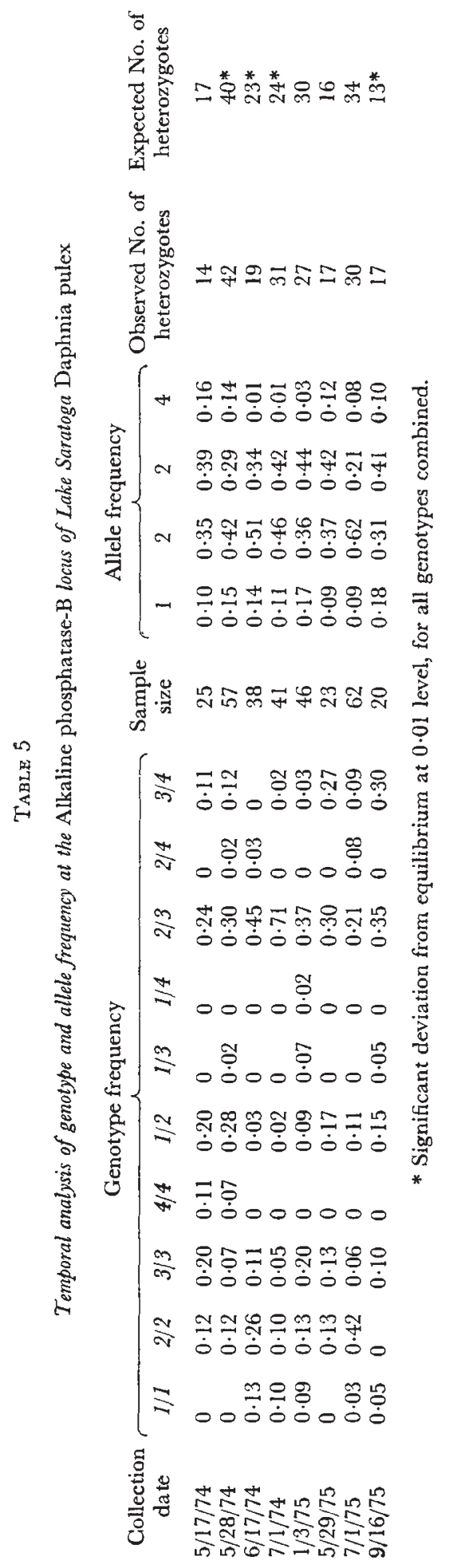


period (tables 5 and 4 ). Where deviations did occur for $A l k-B$ the excess usually involved the $2 / 3$ heterozygote. The sum of all heterozygous classes combined remained near the predicted. At the $E s t-A$ locus the population was not in equilibrium for most of the sample period. In six of eight cases the excess genotype was a homozygote.

\section{Discussion}

Daphnia pulex most frequently reproduces by parthenogenesis. Some question has remained concerning the behaviour of chromosomes during egg formation. According to Mortimer (1936), parthenogenetic oogenesis involves only a single mitotic division. Bacci et al. (1961), however, have noted in their cytological studies what appeared to be synapsis occurring during oogenesis, and concluded that recombination could be going on, and that this would result in allelic segregation. The data for $D$. pulex in table 1 clearly failed to uncover segregation at the loci studied, a result which confirms the work of Hebert and Ward (1972) for D. magna, and of Manning et al. (1977) for Bosmina longirostris, another cladoceran.

Considerable genetic differences were uncovered between the Saratoga and Campus Pond D. pulex populations. These differences were both quantitative and qualitative in nature. While quantitative differences in allele frequency are usually explained by either natural selection, genetic drift, or some combination of the two, as in the case of Hebert's work on D. magna (Hebert 1974a, b, $c$ and $d$ ), qualitative differences are more difficult to interpret. In those cases in which enzyme systems were totally absent in one of the two populations the influence of immediate environment could be ruled out, for the differences persisted through several parthenogenetic generations, under uniform environmental conditions. We are then left with some heritable differences to interpret. Because we have only sampled two populations, and have not made crosses, it is not yet possible to say whether these are genetic differences and, if so, whether they indicate cryptic species, as was recently found for Bosmina (Manning et al., 1977); or whether several races exist which differ both with respect to allozymes and cyclic type.

Successive sampling from the Saratoga population revealed significant fluctuations in gene and genotype frequency during the period studied. Because collections were made at irregular intervals it is impossible to determine whether the patterns of change occur at random, or according to some cycle. However, these same types of change have been noted extensively in permanent populations of D. magna (Hebert, Ward and Gibson, 1972; Hebert, $1974 a$ and $d, 1976)$.

There are several possible explanations which could account for the patterns of change in D. pulex. One is that the lake, in fact, is a mosaic of Daphnia populations which differ from one another extensively in allele and genotype composition. Thus, in sampling over time either different subpopulations are encountered, due to their (or our) pelagic nature, or migration between populations occurs sporadically. In Hebert's work, although most permanent ponds were spatially homogeneous, in the larger Audley End pond subpopulation differentiation was noted (Hebert, 1976). Hebert suggests, in fact, that such differentiation may be important in larger lakes. 
On the other hand recent studies (Manning et al., 1977) on Bosmina longirostris from Lake Washington in Seattle revealed remarkable spatial homogeneity throughout the year. A second possible explanation involves natural selection. In Hebert's work on D. magna it has been shown, in several cases, that changes in parthenogenetic fecundity are responsible for changes in the distribution of genotype frequencies (Hebert, Ward and Gibson, 1972; Hebert, 1974d). Again we have no fecundity data for our samples, so this can only remain a speculation for $D$. pulex. Genetic drift, yet a third explanation, can probably be ruled out in this study, because density measurements revealed populations of rather large size. A fourth, and final, possibility is that the rapid changes in genotype frequency reflect genetic recruitment from ephippial eggs. This seems unlikely, for even if the ephippeal carrying females and males from the year before were enriched for genotypes rare during the following year, one would predict a single, perhaps synchronous perturbation as the hatching cohort appeared. Instead the oscillations seem to occur at odd times, and more than once a year. All of these various hypotheses which could explain the observed fluctuations in genetic composition are subject to experimental analysis and need be tested.

Finally, and quite unlike Hebert's results on D. magna (Hebert, 1974a and $d, 1976$ ), we encountered no consistent tendency for excess heterozygosity at allozyme loci in the large and permanent Saratoga population. At those times when the Saratoga population was not in Hardy-Weinberg equilibrium, it just as often involved homozygote excesses. Although heterozygote excesses which indicate intense selection were common in the one sample we made of Campus Pond $D$. pulex, the genetic uniformity of this population leads us to suspect that the entire population may be derived from a few, and perhaps even one, founders. Comparable studies of geneenzyme variation in Bosmina (Manning et al, 1977) and Sinocephalus (Smith and Fraser, 1976), two other parthenogenetically reproducing cladocera, have also failed to uncover consistent patterns of excess heterozygosity.

Acknowledgments.-We thank Dr Raymond Stross for his advice and assistance during the course of this study. We also gratefully acknowledge Karen Boxer, Steve Litz, and Steve Miller for their help in the electrophoretic work, and Dr Ken Bogden who initiated. the project. This work was supported by an N.S.F. grant.

\section{REFERENCES}

BACCI, G., CognetTI, G., AND VACCARI, A. M. 1961. Endomeiosis and sex determination in Daphnia pulex. Experientia, 17, 505-506.

BANTA, A. M., AND BRoWN, L. A. 1929. Control of sex in cladocera. I. Crowding the mothers as a means of controlling male production. Physiol. Zool., 2, 80-92.

BERGER, E. 1976. Heterosis and the maintenance of enzyme polymorphism. Amer Nat., $110,823-839$.

Brooks, J. L. 1957. The systematics of North American Daphnia. Mem. Conn.. Acad. Arts. Sci., 13, 5-180.

HEBERT, P. D. N. 1974a. Enzyme variability in natural populations of Daphnia magna. II. Genotypic frequencies in permanent populations. Genetics, 77, 323-334.

HEBERT, P. D. N. 1974b. Enzyme variability in natural populations of Daphnia magna. III. Genotypic frequencies in intermittent populations. Genetics, 77, 335-341.

HEBERT, P. D. N., 1974c. Enzyme variability in natural populations of Daphnia magna. I. Population structure in East Anglia. Evolution, 28, 546-556.

HEBERT, P. D. N. 1974d. Ecological differences between genotypes in a natural population. of Daphnia magna. Heredity, 33, 327-337. 
HEBERT, P. D. N. 1976. Enzyme variability in natural populations of Daphnia magna. IV. Ecological differentiation and frequency changes of genotypes at Audley End. Heredity, 36, 331-341.

HEBERT, P. D. N., AND WARD, R. D. 1972. Inheritance during parthenogenesis in Daphnia magna. Genetics, 71, 639-642.

HEBERT, P. D. N., WARD, R. D., AND GIBSON, J. B. 1972. Natural selection for enzyme variants arnong parthenogenetic Daphnia magna, Genet. Res., Camb., 19, 173-176.

HUBBY, J., AND LEWONTIN, R. C. 1966. A molecular approach to the study of genic heterozygosity in natural populations. I. The number of alleles at different loci in Drosophila pseudoobscura. Genetics, 54, 577-594.

LEWontrn, R. C. 1974. The Genetic Basis of Evolutionary Change. Columbia Univ. Press, New York, 346 pp.

MANNING, J., KERFOOT, W. C., AND BERGER, E. M. 1977. Sibling species of Bosmina longirostris uncovered by electrophoresis. Evolution (in the press).

Mortimer, c. H. 1936. Experimentelle und cytologische Untersuchungen über den Generationswechsel der Cladoceren. Zool. Jb. Physiol., 56, 323-388.

oJIMA, Y. 1958. A cytological study on the development and maturation of the parthenogenetic and sexual eggs of Daphnia pulex. Kwansei Gakuin Univ. Ann. Studies, 6, 123-171. SHAW, C. R., AND PRASAD, R. 1970. Starch gel electrophoresis of enzymes-a compilation of recipes. Biochem. Genet., 4, 297-320.

SMTTH, M. Y., AND FRASER, A. 1976. Polymorphism in a cyclic parthenogenetic species: Simocephalus serrulatus. Genetics, 84, 631-637. 